\title{
The study of millennial's attitudes towards the content in Thai digital TV: Case study of Bangkok area
}

\author{
Panapa Chintaradeja \\ Brand Matrix Research Company, Thailand
}



\section{INTRODUCTION}

"Millennials know everything there is to know about social media because we are living it. We are constantly perusing Facebook, Twitter, Instagram, etc., it's how we share and get information" ) Abbot, 2019( . This utterance is remarkably interesting for this research because it shows the characteristics of Millennial generation. Thus, they have grown up with digital devices which is comfortable navigating a variety of online TV platforms and devices. Smartphone has been taken for granted as a norm for them.

To illustrate, Nielson company clarifies that millennial are now the largest generational group in the U.S. which have grown alongside advancements in technology and media platforms, placing them in intriguing territory regarding media habits. When it comes to television, their eyes are glued to the screen. With commercials, they are still tuned in but their eyes are on their cell phones ) Nielson, 2017(. Also, digital resources can deepen millennials' involvement with a TV show, and lots of millennials follow shows and characters on social media. With this critical characteristic, understanding millennials attitudes are essential to plan every kind of the marketing strategies.

Millennials have spending power and influence, and marketers are eager to reach them. Their particular media habits differ vastly from past generations and have a major impact on the overall media landscape and how content is consumed ) Nielson, 2018(. Millennials have helped change the way we do somethings, including how we watch TV. Their habits like binge watching and viewing on demand have rubbed off on us, although most boomers still sit in front a TV set, not a laptop like their kids )Quigley, 2016(. Interestingly, while TV viewing is forecast to drop over the next few years, e-Marketer says online video consumption numbers will grow from 64.2 million this year to 64.8 million in 2019 and 65.1 million by 2020 . Over these three years, about $89 \%$ of Millennials will watch online video )Fitzgerald, 2018(.

However, the general move from analog anything to digital everything certainly plays a role in traditional TV marketing strategies. Also, interactive marketing tactics and quality content in television is needed when dragging digital TV to be strong in media marketing again. However, social media has been the real game-changer, placing the power of relevance distinction in the hands of the consumers. If TV content producer need to win, they need to bring the supply great contents to meet a variety of demand. 
Furthermore, the increasing number of streaming services brings an effect on digital TV channels. Millennials people more watch their favorite shows through Netflix, Amazon Prime Video, Hulu, and other similar services. This is the reason why digital TV networks have also been working double time in strengthening their content marketing. Moreover, content becomes easier for everyone to create. Everyone can watch, read, or share the content after they are ready to publish it. It creates a far more relaxed atmosphere and allows us to easily focus on quality over quantity. On-demand content strategy makes it far easier and comfortable for everyone to enjoy our content without the added stress. In addition, content is timeless. This is often the case when someone wants to access their favorite content through the smartphone everywhere in the world.

In the light of this research, analyzing attitudes towards digital TV viewed through the prisms of generations will shows solid results to TV show owner and producer that 'what are the millennial's attitudes towards the content in Thai digital TV in disruptive technology era. The study has research questions as follows.

1. What are the millennial's attitudes towards the content in Thai digital TV?

2. How is the intention of millennial people to in relation to watching Thai digital TV?

\section{LITURATURE REVIEW}

This part states the research, which is conducted regarding the concepts of television watching, generation and consumption practices as followings:

Firstly,)Launglaor \& Lealaphan, 2017( focuses on channels, types of program and factors influencing television watching thru digital TV of Gen M in Bangkok Metropolitan. Findings include that the majority of sample, which was male, aged between 18-21 years with income between 5,001-10,000 baht and are undergraduate and post graduated level, watch Channel 3 the most. This is followed by Channel 7 and Channel one. The type of programs with the highest watching score are Thai dramas, variety shows, and music shows, respectively. Those viewed the most are at Channel 3, Channel one, and Channel 7. Factors influencing TV watch include having TV programs as friend, not lonely or isolated, and they help to release tension from studying and working. The satisfaction they get from watching Thai dramas depends mainly on the script and content, actors/ actresses, and professionality of actors/actresses.

Secondly, )PATCH, 2018( studies 'which factors influence Generation Z's content selection in OTT TV?' The purpose of this study is to understand which user interface components Generation $Z$ takes into consideration when selecting content in OTT TV. Multiple methodologies were selected to investigate these media habits. Think-aloud usability testing and interview determined Generation Z's natural media behavior while browsing OTT content. Online survey data was collected from a broader sample, comparing Generation Z and Generation Y. It was discovered that both generations have similar behaviors in which user interface components influence content choice. The research also revealed trends in which components are important to Generation $\mathrm{Z}$ and why. This research is the first step to making informed and data-driven decisions in the design and implementation of OTT TV platforms for Generation Z, thus lessening cognitive overload and creating optimal user experiences.

Thirdly, ) Podara, Matsiola, Maniou,, \& Kalliris, 2019( aim to explore and assess the transformations of audiovisual consumption practices within the current digital environment. Specifically, the research focuses on examining audiovisual consumption patterns on documentary viewing utilizing focus group method; Greece and Cyprus were selected as case study locations, due to their interconnected culture and origins. The results are presented in a dual level, initially the ways post-millennials of Greece and Cyprus consume web \& traditional documentaries are examined. Moreover, the patterns of audiovisual content consumption, comparing to previous generations, are explored.

According to the literature reviews, they show the significances different generations which are related to content selection and television watching behavior. In terms of this study, this research will investigate the differences from those literature reviews by focusing on the study of attitudes towards the content in Thai digital TV.

\section{METHOD}

Scope of this research of attitudes.

1.Content: Millennial's attitudes towards the content in Thai digital TV which is framed by ABC model

2.Population and samplings: Millennial people which are recruited by convenience sampling. The researcher collects the data until the description become repeated and then confirm with the previously collected data. Then, data collection will be terminated.

3. Area: Bangkok

4.Time period: 3 months

Definition of terms

Millennial: the generation of people born between 1980 and 2000 who have lived in Bangkok area.

Attitudes: ABC model of attitudes which includes 
1) Affective - feeling

2) Behavior-intention

3) Cognition-believe

Thai digital TV: digital TV is an evolution of the utilization of radio frequencies in which efficiency will be way higher than that of the analogue system in Thailand.

\section{Type of research and tool}

Qualitative methods with the phenomenology method which the researcher focuses on individual experience by using the in-depth interview with open-ended questions to be a tool for data gathering and analyze focusing on discern the essence of the lived experiences.

\section{Data analysis}

This research takes 'thematic analysis' for granted because it allows a closeness to data, unobtrusive means of analyzing interactions and it provides insight into complex models of human thought and language use.

\section{RESULT AND DISCUSSION}

The data of samples are gathered from 30 Millennial participants which are illustrated the general demographics as Figure 1.

Gender

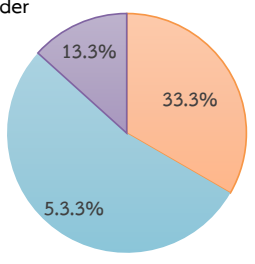

Education

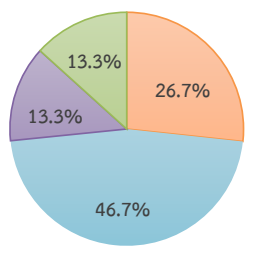

Income

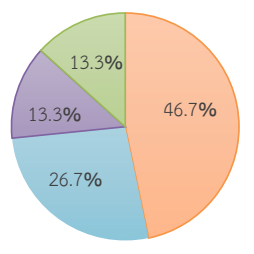

$\square$ male

female

$\square$ queer

bachelor

$\square$ master

$\square$ etc.

$\square 0-9,999$

10,000 - 19,999

$\square 20,000-29,999$

$\square 30,000-39,999$
Ages

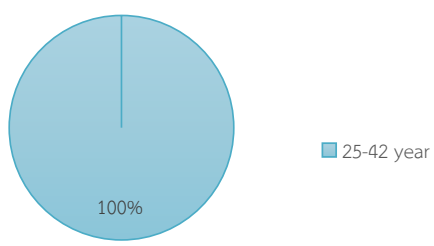

Occupation

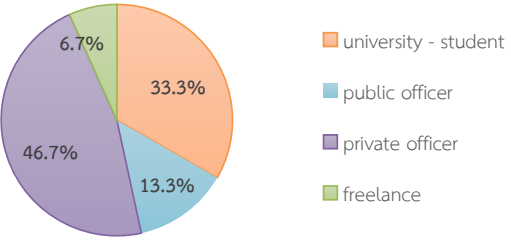

Figure 1 Demographic information

Finding of attitudes towards the content in Thai digital which is categorized in themes.

Affective - feeling regarding content

Too many advertisings: Most of them understand the need for advertising on commercial TV channels, but the recent increase in the number of minutes permitted per hour seems to be just too much. Moreover, there are too many ads in TV. When watching the favorite television shows, it seems they stop the show for commercials all the time. There are advertisements everywhere they are on TV nonstop.

Too many rerun programs: Most of them agree that viewers could catch a favorite show on cable instead watching the rerun on TV only. No matter what kind of content they want, they can catch it with smartphone immediately, do not need to wait for rerun anymore. These days, reruns are tucked in just before prime-time lineups and now binge viewers had better catch them online with services such as Amazon, Hulu and Netflix. 
The content is too many singing contests: It is very boring to see everybody sings, sings, sings and sings. The audiences demand to the TV producer that please keep concerning that not everybody in Thailand can be a good singer. It is very irritating on TV.

News content: The content of the news is not up to dated and on time at all. However, for the news content, Facebook is so much better, on time and real in terms of hot issues.

Behavior-intention

Watching intention: They still watch but with smartphone to cross-check the news. They do not want to watch the news from digital TV anymore because smart phone is quicker for updating the critical situations. They turn on TV accompany themselves only not paying attention to watch. They watch only morning news while dressing up and can not touch their smart phone. They watch TV only watch sport match because the demanding of big screen TV for maximum fun. They watch because they want to hang out and make good relationships with their families sometimes only.

Cognition-believe regarding content

They believe that the quality program and content must come from TV producer which is responsible for overseeing all aspects of a show and ensuring the cast and crew turn out a quality product to audiences. They believe that YouTube TV content offers more a variety of channels many features, and solid performances. It is totally replicated the digital TV program. They believe that the content and style in digital TV is old-fashioned for old people and senior citizen not for new generation anymore in the era of disruptive technology. They believe that the only good thing for digital TV is the audiences do not need an internet connection, while watching shows on TV. On the contrary, digital TV is not portable and compact, the audiences cannot carry them around and entertain themselves everywhere. Digital TV cannot communicate and connect with people, find a destination on maps, or do anything useful with them except watching advertising with entertainment. They believe that when watching digital T.V, it seems like forcing to watch the content whatever comes up, with constant and rerun commercials.

\section{CONCLUSION}

In sum, the characteristics and consumption habits of the millennials and future generations is constantly changing. Furthermore, the number of digital content subscriptions and the consumption of live programming are steadily rising. Accordingly, digital TV need to adapt themselves to the new generation's lifestyle and create the modern marketing to keep millennial and future generation to interested in the content in digital TV. To support, (Schouw, 2018) explains that due to digitalization the television industry has changed rapidly over the last few years. Industry disrupters like Netflix have changed the way individuals consume television. The consumption of nonlinear television is not restricted by time, place, or content.

However, technological innovations have changed viewing modes and allow users to control what, when, where, and how they view programs. Further, platform and content choices have been greater than ever before. Since it appears that the way millennials consume television has changed. Finally, in the era of Facebook and YouTube rule the roost, digital TV need to change and do huge R\&D to progress the content in TV program and stand strongly in competitive marketing because millennials are both skillful internet users and consumer content.

\section{REFERENCES}

Abbot, L. (2019). LinkedIn.com. Retrieved from 11 Millennials' traits you should know about before you hire Them: https://business.linkedin.com/talent-solutions/blog/2013/12/8-millennials-traits-you-shouldknow-about-before-you-hire-them

Fitzgerald, T. (2018). Forbes. Retrieved from Wow: Millennials watch more online video than traditional television: https://www.forbes.com/sites/tonifitzgerald/2018/11/28/wow-millennials-watch-moreonline-video-than-traditional-television/\#2e7f79724138

Launglaor, W., \& Lealaphan, A. (2017). A study on channels, types of programs and factors influencing television watching thru digital TV of Gen M in Bangkok metropolitan. University of Thai Chamber of Commerce Journal, 65-78.

Nielson. (2018). Millenials on millenials: TV and digital news consumption. Retrieved from Nielson.com: https://www.nielsen.com/us/en/insights/report/2018/millennials-on-millennials-tv-digital-newsconsumption/

Nielson, C. (2017). Millenials on millenials: A look at viewing behavior distraction and social media stars. Retrieved from Nielsen.com: https://www.nielsen.com/us/en/insights/article/2017/millennials-onmillennials-a-look-at-viewing-behavior-distraction-social-media-stars/

Patch, H. (2018). Which factors influence Generation Z's content selection in OTT TV? Stockholm, Sweden : Project in Computer Science and Engineering. 
Podara, A., Matsiola, M., Maniou,, T. A., \& Kalliris, G. (2019). Transformations of television consumption practices: An analysis on documentary viewing among post-millennials. Journal of Audeiences and Reception Studies, 68-87.

Quigley, M. W. (2016). Tune In to Millennials' TV Viewing Habits. Retrieved from AARP: https://www.aarp.org/home-family/friends-family/info-2016/millennials-tv-viewing-habits.html

Schouw, L. (2018). "To binge or not to binge" The online Viewing Habits of Dutch millennials. Rotterdam: Erasmus University . 